\title{
Technical note: In situ ruminal starch disappearance kinetics of hull-less barley, hulled barley, and corn grains
}

\author{
G. Ferreira, ${ }^{, 1}$ Y. Yang, ${ }^{*}$ C. L. Teets, ${ }^{*}$ W. S. Brooks, $\dagger$ and C. A. Griffey $†$ \\ *Department of Dairy Science, and \\ †Department of Crop and Soil Environmental Sciences, Virginia Tech, Blacksburg 24061
}

\begin{abstract}
The objective of this study was to compare ruminal starch disappearance rates of hull-less barley, hulled barley, and corn grains. Five different genotypes were used for each of the 2 barley types. In addition, each of these genotypes was grown in 2 different locations and years, resulting 10 independent barley samples for each of the 2 barley grain types. Five different genotypes of corn grain were obtained from a commercial seed company. After being ground to pass through a 4-mm screen of a cutter mill, $3.6 \mathrm{~g}$ of each grain was placed into a porous bag, which was then incubated in the rumen of 2 ruminally cannulated cows for $0,4,8,12$, 24 , and $48 \mathrm{~h}$. Corn grains had greater instant ruminal starch disappearances than barley grains (22.4 and $8.2 \%$, respectively). Instant ruminal starch disappearances did not differ between hulled and hull-less barley grains. Ruminal starch fractional disappearance rates were greatest for hulled barley grains, moderate for hull-less barley grains, and lowest for corn grains (15.3, 13.9 , and $7.1 \% / \mathrm{h}$, respectively). Ruminal starch halflife was shortest for hulled and hull-less barley grains $(4.4 \mathrm{~h})$ and longest for corn grains $(6.6 \mathrm{~h})$. Ruminal starch half-life did not differ between hulled barley and hull-less barley grains. In conclusion, using a holistic experimental design and statistical analysis, this study showed that starch from hull-less barley grains has a ruminal half-life similar to that of hulled barley grains and shorter than that of corn grains.
\end{abstract}

Key words: hull-less barley, hulless barley, in situ, starch half-life

\section{Technical Note}

Cereal grains, such as corn, sorghum, barley, wheat, and oats, are included as an energy source in rations

Received January 29, 2018.

Accepted March 9, 2018.

${ }^{1}$ Corresponding author: gonf@vt.edu for lactating dairy cows. Cereal grains contain high concentrations of starch, a component that is almost completely and uniformly digested in the gastrointestinal tract when processed adequately (Van Soest, 1994; Ferreira and Mertens, 2005; Yang et al., 2017). However, differences exist for ruminal starch disappearance rates among cereal grains. For instance, starch degradability in the rumen is greater for wheat and hulled barley than for corn and sorghum (Herrera-Saldana et al., 1990).

A few studies have determined the ruminal disappearance rates of starch from hull-less barley (Yang et al., 1997, 2013). Yang et al. (1997) measured the in situ ruminal starch disappearance rate of hulled barley, hullless barley, and corn grains, and reported that starch from hull-less barley disappeared faster than starch from corn but slower than starch from hulled barley. Yang et al. (2013) compared the in situ ruminal starch disappearance rate of 4 genotypes of hull-less barley against 1 genotype of hulled barley, and reported an in situ ruminal starch disappearance rate for hull-less barley that was similar to or slower than that of hulled barley. From these studies, it could be concluded that starch from hull-less barley disappears at slower rates than starch from hulled barley. From the perspective of experimental design, however, these 2 studies (Yang et al., 1997, 2013) lacked the true sense of replication, because a single or only a few hull-less barley grain sources were compared with a single hulled barley grain source. Because of the lack of actual replication, making a broad conclusion contrasting the starch disappearance rates of hulled and hull-less barley grains is not reasonable. This flaw is also applicable to the study of Herrera-Saldana et al. (1990), in which single grain sources were compared with each other without using independent sources of each grain as actual replicates.

In this study, we hypothesized that starch from hull-less barley disappears in the rumen more slowly than starch from hulled barley grains and faster than starch from corn grain. Therefore, our objective was to compare ruminal starch disappearance rates of hull-less barley, hulled barley, and corn grains. To actually com- 
pare the ruminal starch disappearance rates of these grains, multiple and independent sources were used as random and independent replicates for each grain type.

Hulled and hull-less barley grains were obtained from the Small Grains Breeding Program of the Department of Crop and Soil Sciences at Virginia Tech (Blacksburg). For each of the 2 barley types (i.e., hulled and hull-less barley), 5 genotypes were used. In addition, each of these genotypes was grown in 2 diverse environments (different locations and years), resulting in a total of 10 independent barley samples for each of the 2 barley grain types. Five genotypes of corn grain were obtained from a commercial seed company (Dupont-Pioneer, Johnston, IA). Each of the 25 grain samples (Table 1) was ground to pass through the 4-mm screen of a Wiley cutter mill (Thomas Scientific, Swedesboro, NJ). For each of the 25 grain samples, 12 porous Dacron bags (R1020, Ankom Technology, Macedon, NY) were filled with $3.6 \mathrm{~g}$ (DM basis) of ground material and sealed. Bag dimensions were $10 \mathrm{~cm}$ wide and $20 \mathrm{~cm}$ long, and bag pore size was $50 \pm 10 \mu \mathrm{m}$. The sample amount to bag surface ratio was approximately $9 \mathrm{mg} / \mathrm{cm}^{2}$ (Ferreira and Mertens, 2005). In addition to an empty bag that served as a blank sample, 6 bags of each of the 25 grain samples were placed in 1 of 12 larger net bags (i.e., laundry-type bags). The Institutional Animal Care and Use Committee (IACUC) of Virginia Tech approved all procedures involving dairy cows. At $0930 \mathrm{~h}$ on the test day, all bags were simultaneously immersed within the rumen of 2 cannulated cows fed a TMR containing $40 \%$ corn silage, $7 \%$ alfalfa hay, and $53 \%$ concentrate mix (DM basis). Feed was delivered once daily at $0900 \mathrm{~h}$. Bags were incubated for $0,4,8,12,24$, and $48 \mathrm{~h}$. For the 0 -h incubation, bags were totally immersed into the liquid phase of the ventro-distal cavity of the rumen and extracted after $10 \mathrm{~s}$. Once the incubations were finished, bags were placed in a bucket with water and ice to stop bacterial fermentation, rinsed 5 times (3-min washing + spinning cycles) using a washing machine (SKY2767, Best Choice Products, Irvine, CA), and dried in a forced-air oven at $55^{\circ} \mathrm{C}$ for $48 \mathrm{~h}$. Once dried, all bags were weighed, opened, and the residues were reground for starch analysis. Residues were reground to pass through a $0.5-\mathrm{mm}$ screen of a cyclone mill (Udy Corp., Fort Collins, CO) for samples incubated for 0, 4, 8, and $12 \mathrm{~h}$. Due to the small amount of residue remaining after incubation, residues were reground using a mortar and pestle for samples incubated for 24 and 48 h. Starch concentrations were determined using the acetate buffer method of Hall (2009) with $\alpha$-amylase from Bacillus licheniformis (FAA, Ankom Technology) and amyloglucosidase from Aspergillus niger (E-AMGDF, Megazyme International, Wicklow, Ireland).
Disappearance kinetic parameters were estimated using the NLIN procedure of SAS (version 9.4, SAS Institute Inc., Cary, NC), and according to equation [1] (Ørskov and McDonald, 1970):

$$
\text { Disappearance }(\%)=A+B \times\left(1-e^{(-k \times T)}\right) \text {, }
$$

where $T$ is the time of incubation (h), $A$ is the pool of immediately available starch $(\%)$ at time $T=0$, $B$ is the pool of potentially available starch, and $k$ is the fractional disappearance rate $(\% / \mathrm{h})$ of pool $B$. The half-life of grain starch $\left(\boldsymbol{T}_{\mathbf{5 0}}\right)$, which we defined as the time at which $50 \%$ of the initial starch disappeared, was estimated according to equation [2]:

$$
T_{50}(\mathrm{~h})=\log \left(1-\left(\frac{50-A}{B}\right)\right) e^{-k}
$$

After estimating the kinetic parameters for each grain replicate $(\mathrm{n}=50)$, differences in kinetic parameters among grains were analyzed using the MIXED procedure of SAS (version 9.4, SAS Institute Inc.). To test our hypothesis, we challenged the null hypothesis $\mathrm{H}_{0}$ : " $T_{50}$ of hulled barley $=T_{50}$ of hull-less barley $=T_{50}$ of corn" and the alternative hypothesis $\mathrm{H}_{\mathrm{A}}$ : " $\mathrm{H}_{0}$ is not accepted." Data were analyzed as a completely randomized design using a model that included the effects of cow (random, $\mathrm{df}=1$ ), grain type (fixed, $\mathrm{df}=2$ ), and the residual error (random, $\mathrm{df}=46$ ). Differences between grain types were tested using the pdiff option in SAS.

Corn grains had greater $(P<0.01)$ instant ruminal starch disappearances than barley grains (22.4 and $8.2 \%$, respectively; Table 2; Figure 1). Instant ruminal starch disappearances did not differ between hulled and hull-less barley grains $(P=0.35)$. Ruminal starch fractional disappearance rates were greatest for hulled barley grains, moderate for hull-less barley grains, and lowest for corn grains $(15.1,13.7$, and $6.9 \% / \mathrm{h}$, respectively). Ruminal starch half-life was shortest for hulled and hull-less barley grains $(4.4 \mathrm{~h})$ and longest for corn grains $(6.6 \mathrm{~h})$. Ruminal starch half-life did not differ

Table 1. Descriptive statistics of starch concentration (\%) of hulled barley $(\mathrm{n}=10)$, hull-less barley $(\mathrm{n}=10)$, and corn $(\mathrm{n}=5)$ grains

\begin{tabular}{lcccc}
\hline Grain & Average & SD & Minimum & Maximum \\
\hline Hulled barley & 57.6 & 2.7 & 50.9 & 60.3 \\
Hull-less barley & 62.8 & 1.5 & 60.3 & 64.9 \\
Corn & 70.9 & 6.3 & 64.0 & 80.2 \\
\hline
\end{tabular}


Table 2. In situ ruminal disappearance kinetic parameters ${ }^{1}$ for hulled barley $(\mathrm{n}=10)$, hull-less barley $(\mathrm{n}=$ $10)$, and corn $(\mathrm{n}=5)$ grains

\begin{tabular}{lrrrrc}
\hline Parameter & $\begin{array}{c}\text { Hulled } \\
\text { barley }\end{array}$ & $\begin{array}{c}\text { Hull-less } \\
\text { barley }\end{array}$ & Corn & SEM & $P$-value \\
\hline Instant disappearance $(A), \%$ & $9.1^{\mathrm{b}}$ & $7.2^{\mathrm{b}}$ & $22.4^{\mathrm{a}}$ & 2.7 & 0.01 \\
Potentially available $(B), \%$ & $90.5^{\mathrm{b}}$ & $92.4^{\mathrm{b}}$ & $75.7^{\mathrm{a}}$ & 2.5 & 0.01 \\
Undegradable $(C), \%$ & $0.4^{\mathrm{b}}$ & $0.4^{\mathrm{b}}$ & $1.9^{\mathrm{a}}$ & 0.2 & 0.01 \\
Fractional disappearance rate $(k), \% / \mathrm{h}$ & $15.3^{\mathrm{d}}$ & $13.9^{\mathrm{e}}$ & $7.1^{\mathrm{f}}$ & 0.6 & 0.01 \\
Ruminal half-life $\left(T_{50}\right), \mathrm{h}$ & $4.1^{\mathrm{b}}$ & $4.6^{\mathrm{b}}$ & $6.6^{\mathrm{a}}$ & 0.3 & 0.01 \\
\hline
\end{tabular}

${ }^{\mathrm{a}-\mathrm{f}}$ Means within a parameter with different letters differ $\left({ }^{\mathrm{a}-\mathrm{c}} P<0.01\right.$ or $\left.{ }^{\mathrm{d}-\mathrm{f}} P<0.05\right)$.

${ }^{1}$ Disappearance kinetic parameters were determined according to the models described by Ørskov and McDonald (1970).

between hulled barley and hull-less barley grains $(P=$ $0.25)$.

Evaluating disappearance rates using a single source for each grain type (Herrera-Saldana et al., 1990; Yang et al., 1997) can likely lead to erroneous conclusions. For example, depending on the single grain source tested, a researcher might conclude that hull-less barley grain has a faster ruminal starch disappearance rate than corn grain (Figure 2A) or that corn grain has a faster ruminal starch disappearance rate than hullless barley grain (Figure 2B). In the current study, we tested our hypothesis under a broader statistical scope, whereby multiple grain sources for each grain type were used instead of a single grain source for each grain type (Herrera-Saldana et al., 1990; Yang et al., 1997, 2013). In statistical terms, using independent grain sources as random replicates of grain type challenges the null hypothesis $\mathrm{H}_{0}$ : "all grains have the same ruminal starch disappearance rates" under a more holistic scope.

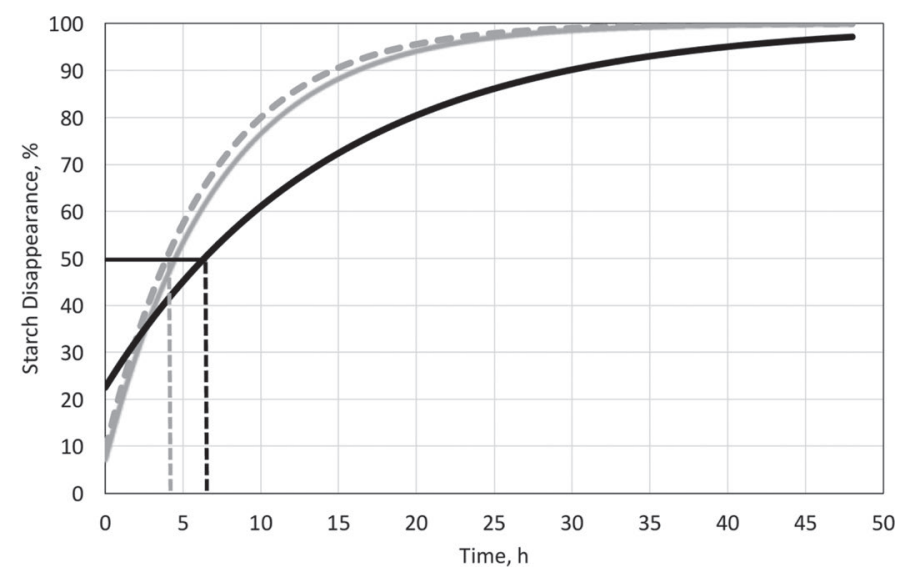

Figure 1. In situ ruminal starch disappearance of hulled barley (n $=10$; dashed gray line), hull-less barley $(\mathrm{n}=10$; solid gray line), and corn $(\mathrm{n}=5$; solid black line) grains. The vertical dotted lines represent the ruminal half-life of starch $\left(T_{50}\right)$, which is the time at which $50 \%$ of the total starch disappeared. Starch of barley grains disappeared faster than starch of corn grains ( $T_{50}=4.4 \mathrm{~h}$ and $T_{50}=6.6 \mathrm{~h}$, respectively).
A

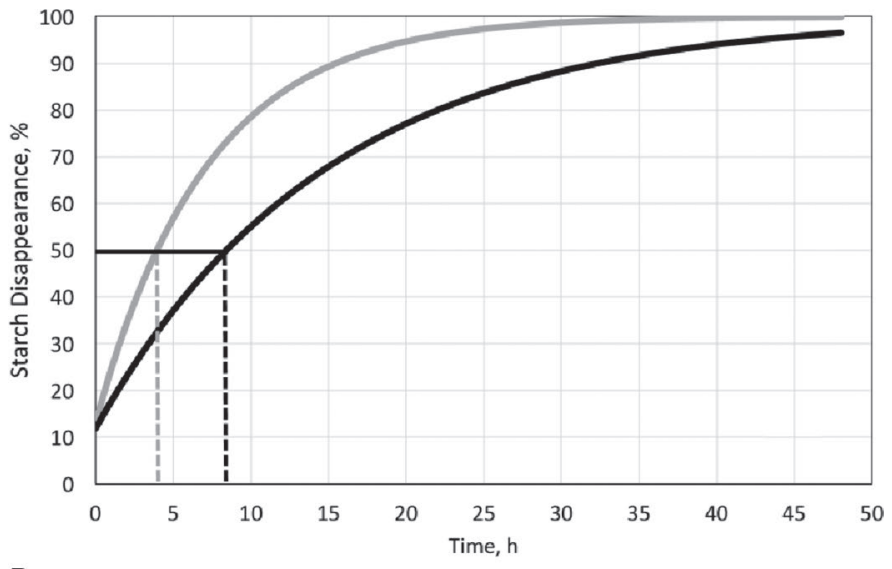

B

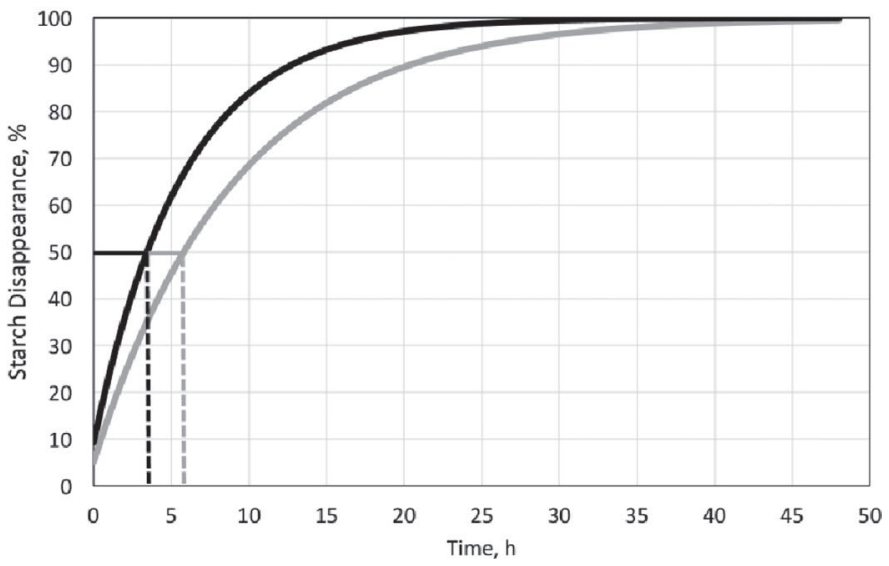

Figure 2. In situ ruminal starch disappearance of hull-less barley (gray lines) and corn (black lines) grains. Each line represents the starch disappearances measured in 2 cows for a single grain. The vertical dotted lines represent the ruminal half-life of starch $\left(T_{50}\right)$, which is the time at which $50 \%$ of the total starch disappeared. In A, starch from hull-less barley disappeared faster than starch from corn $\left(T_{50}=\right.$ 4.0 and $T_{50}=8.4 \mathrm{~h}$, respectively). In B, starch from corn disappeared faster than starch from hull-less barley $\left(T_{50}=3.7 \mathrm{~h}\right.$ and $T_{50}=5.9 \mathrm{~h}$, respectively). 
Sudden rumen loads of VFA and lactic acid are the main drivers leading to rumen upsets such as subacute ruminal acidosis. The load of these acids will depend on extrinsic factors such as adequate concentrations of physically effective NDF (Mertens, 1997), or to intrinsic dietary factors such as fermentability of the dietary components. In cereal grains, 2 pools of starch will affect the load of VFA and lactic acid in the rumen: a first pool of immediately available starch that is described by the soluble starch at time 0 (parameter $A$ in equation [1]), and a second pool of potentially available starch (parameter $B$ in equation [1]) that is described by the fractional disappearance rate (parameter $k$ in equation [1]). Considering the pool of soluble or immediately available starch (Ørskov and McDonald, 1970; Herrera-Saldana et al., 1990), the ruminal starch disappearance rate at time zero was greatest for corn grains $(22.5 \%)$ and least for hulled $(9.2 \%)$ and hullless $(7.3 \%)$ barley grains (Table 2). Therefore, when considering this first pool, the load of VFA and lactic acids would be greater for diets containing corn grains than for those containing barley grains. However, when considering the pool of potentially fermentable starch (Ørskov and McDonald, 1970; Herrera-Saldana et al., 1990), the starch fractional disappearance rate was maximal for hulled barley grains $(15.1 \% / \mathrm{h})$, intermediate for hull-less barley grains $(13.7 \% / \mathrm{h})$, and minimal for corn grains $(6.9 \% / \mathrm{h}$; Table 2$)$. Therefore, when considering this second pool only, the load of VFA and lactic acids would be greater for diets containing barley grains than for diets containing corn grain. This counterbalance between pools has been reported in some previous studies (Yang et al., 1997; Foley et al., 2006; Yang et al., 2013) but not in others (Herrera-Saldana et al., 1990). From a kinetics perspective, this counterbalance hinders interpretations and comparisons related to starch fermentability among cereal grains. In the current study, we propose a ruminal starch half-life as a comparable measure of ruminal starch disappearance rate that includes both starch pools (i.e., immediately and slowly available starch pools). Analogous to the affinity constant $\left(K_{m}\right)$ in Michaelis-Menten reactions (Nelson and Cox, 2000), we defined the starch half-life of the grain as the time needed to ferment $50 \%$ of the starch contained in the grain (Table 2; Figures 1 and $2)$. In the current study, the mean half-life of starch in the rumen was shorter for barley grains (4.1 and $4.6 \mathrm{~h}$ for hulled and hull-less barley, respectively) and longer for corn grains (6.6 h; Table 2). It is worth emphasizing in this analysis that starch of certain corn grains fermented as quickly as starch of barley grains (Figure $2 \mathrm{~B}$ ), perhaps due to differences of endosperm vitreousness (Correa et al., 2002) or prolamin concentrations in the endosperm (Kung et al., 2014). In practical terms, and against frequent expectations (Silveira at al., 2007), this means that corn-based diets can be as aggressive as barley-based diets depending on the materials being utilized. In future studies, the dairy nutrition scientific community should be more descriptive and report kinetic parameters, such as pool sizes, fractional disappearance rates, and half-life values of the grains utilized to better explain and understand the results of production performance and nutrient utilization studies when feeding different grain sources or grain processing methods.

Using a holistic experimental design and statistical analysis, we concluded that starch from hull-less barley grains has a ruminal half-life similar to that of hulled barley grains and shorter than that of corn grains. These conclusions imply that feeding diets containing hull-less barley grains has the potential of increasing rumen loads of VFA and lactic acid to a greater extent than feeding diets containing corn grains.

\section{ACKNOWLEDGMENTS}

We thank Jonathan M. Wallace (undergraduate student from the Department of Dairy Science at Virginia Tech) for his assistance in this project. We also thank Dupont-Pioneer (Johnston, IA) for donating the corn grains. This project was partially funded by the John Lee Pratt Endowment from the College of Agriculture and Life Sciences at Virginia Tech, by the USDANational Institute for Food and Agriculture (NIFA, Washington, DC) Hatch Project VA-160025 and by the USDA-NIFA Multistate Project VA-136291 (NC-2042, Management Systems to Improve the Economic and Environmental Sustainability of Dairy Enterprises).

\section{REFERENCES}

Correa, C. E. S., R. D. Shaver, M. N. Pereira, J. G. Lauer, and K. Kohn. 2002. Relationship between corn vitreousness and ruminal in situ starch degradability. J. Dairy Sci. 85:3008-3012.

Ferreira, G., and D. R. Mertens. 2005. Chemical and physical characteristics of corn silages and their effects on in vitro disappearance. J. Dairy Sci. 88:4414-4425.

Foley, A. E., A. N. Hristov, A. Melgar, J. K. Ropp, R. P. Etter, S. Zaman, C. W. Hunt, K. Huber, and W. J. Price. 2006. Effect of barley and its amylopectin content on ruminal fermentation and nitrogen utilization in lactating dairy cows. J. Dairy Sci. 89:43214335 .

Hall, M. B. 2009. Determination of starch, including maltooligosaccharides, in animal feeds: Comparison of methods and a method recommended for AOAC Collaborative Study. J. AOAC Int. 92:42-49.

Herrera-Saldana, R. E., J. T. Huber, and M. H. Poore. 1990. Dry matter, crude protein, and starch degradability of five cereal grains. J. Dairy Sci. 73:2386-2393.

Kung, L., Jr., M. C. Windle, and N. Walker. 2014. The effect of an exogenous protease on the fermentation and nutritive value of highmoisture corn. J. Dairy Sci. 97:1707-1712. 
Mertens, D. R. 1997. Creating a system for meeting the fiber requirements of dairy cows. J. Dairy Sci. 80:1463-1481.

Nelson, D. L., and M. Cox. 2000. Lehninger Principles of Biochemistry. 3rd ed. Worth Publishers, New York, NY.

Ørskov, E. R., and I. McDonald. 1970. The estimation of protein degradability in the rumen from incubation measurements weighted according to rate of passage. J. Agric. Sci. (Camb.) 92:499-503.

Silveira, C., M. Oba, K. A. Beauchemin, and J. Helm. 2007. Effect of grains differing in expected ruminal fermentability on the productivity of lactating dairy cows. J. Dairy Sci. 90:2852-2859.

Van Soest, P. J. 1994. Nutritional Ecology of the Ruminant. 2nd ed. Cornell University Press, Ithaca, NY.
Yang, L., D. A. Christensen, J. J. McKinnon, A. D. Beattie, and P. Yu. 2013. Effect of altered carbohydrate traits in hulless barley (Hor deum vulgare L.) on nutrient profiles and availability and nitrogen to energy synchronization. J. Cereal Sci. 58:182-190.

Yang, W. Z., K. A. Beauchemin, B. I. Farr, and L. M. Rode. 1997. Comparison of barley, hull-less barley, and corn in the concentrate of dairy cows. J. Dairy Sci. 80:2885-2895.

Yang, Y., G. Ferreira, C. L. Teets, B. A. Corl, W. E. Thomason, and C. A. Griffey. 2017. Effects of feeding hull-less barley on production performance, milk fatty acid composition, and nutrient digestibility of lactating dairy cows. J. Dairy Sci. 100:3576-3583. 